\section{Anterior and Medial Angulations of the Styloid Process in Subjects with TMD: Clinical and Radiographic Findings}

Marcelo Oliveira Mazzetto ${ }^{1}$, Kelly Machado de Andrade ${ }^{1}$, Laís Valencise Magri ${ }^{1}$, Carolina Almeida Rodrigues ${ }^{1}$, Plauto Christopher Aranha Watanabe ${ }^{2}$
'Department of Restorative Dentistry, Ribeirão Preto Dental School, USP - University of São Paulo, Ribeirão Preto, SP, Brazil ${ }^{2}$ Department of Department of Morphology, Physiology and Basic Pathology, Ribeirão Preto Dental School, USP - University of São Paulo, Ribeirão Preto, SP, Brazil

Correspondence: Prof. Dr. Marcelo Oliveira Mazzetto, Avenida do Café S/N, 14040-904 Ribeirão Preto, SP, Brasil. Tel: +55-16-36024087. Fax: +55-16-3602-4781.

e-mail: mazzetto@forp.usp.br

\begin{abstract}
This study investigated the existence of association between the angulation of the styloid process on the anterior and medial directions with the intensity of temporomandibular dysfunction (TMD) symptoms. Fifty patients (8 men and 42 women) aged 25 to 70 years, with relevant TMD symptoms were evaluated. Clinical examinations were performed to determine the severity of TMD symptoms (orofacial pain, headache, tinnitus and dizziness) based on the RDC/TMD criteria and the visual analogue scale (VAS), and digital radiographic images of the styloid process were obtained: lateral cephalometric skull radiograph (analysis of anterior angulation) and posteroanterior skull radiograph (reverse Towne's projection) (analysis of medial angulation). The anterior angulation average of the styloid process was $20.89^{\circ}$ while the medial angulation average was $19.1^{\circ}$ in the right side and $19.04^{\circ}$ in the left side. There was no statistically significant difference among the patient groups (severe, moderate and mild symptoms) associating the TMD symptoms and the anterior or medial angulation of the styloid process $(p>0.05)$. There was no correlation between the intensity of the TMD symptoms and the measurements of anterior and medial angulation of the styloid process using either lateral cephalometric or posteroanterior radiographs (reverse Towne's projection).
\end{abstract}

\section{Introduction}

Orofacial pain and temporomandibular dysfunction (TMD) are increasingly common problems in dentistry today and the number of patients who seek care due to these conditions has risen considerably. It is estimated that 40 to $75 \%$ of the general population have some sign of TMD and $33 \%$ have at least one symptom $(1,2)$. TMD is a collective term that covers a large number of clinical problems involving the chewing muscles and/ or temporomandibular joint (TMJ) (3). This dysfunction generates a range of signs and symptoms that are often similar to those of other disorders or diseases. Among the most frequent TMD signs and symptoms are pain in the TMJ or preauricular region, limitation or asymmetry of mandibular movements, joint noises and sounds, referred pain, headaches, tinnitus, earache, dizziness, feeling of ear fullness and hyperacusis (4-6).

Several studies have correlated orofacial pain symptoms with Eagle syndrome (7-9), which consists on anatomical alterations in the styloid process (elongation of the styloid apophysis) or stylohyoid ligament and can produce clinical manifestations similar to those of TMD. Dentists are not quite familiar with this condition and frequently attribute the symptoms of Eagle syndrome to other causes (10). On the other hand, not all morphological alterations in the styloid process producing painful symptomatology are necessarily associated with Eagle syndrome. An accurate evaluation of the styloid process should include a complete and detailed review of the patient's clinical history, palpation of the region (11), oblique lateral radiograph of the mandible and TMJ, anteroposterior radiograph (12), and a panoramic anteroposterior or posteroanterior projection of the TMJ and a modified Towne's position.

The direction and angle of the styloid process may be responsible for the irritation of anatomical structures. An accentuated lateral deviation may cause the tip of the styloid process to press the external carotid artery. A posterior deviation of the elongated styloid process can irritate the last four cranial nerves, internal carotid artery and internal jugular vein. And a medial deviation may invade the tonsil causing painful symptoms. Anterior angulation can result in mucosal irritation and pressure on vital structures in the tonsils. The aim of this study was to correlate the angulation of the styloid process in the anterior and medial directions, with the intensity of TMD symptoms in order to determine a possible association.

\section{Material and Methods}

The research protocol was approved by the local Ethics Committee (Protocol \#2008.1.1058.58.3). The participants were 50 patients with relevant symptoms to TMD and orofacial pain for more than 3 months, who had been randomly screened for orofacial pain treatment at the Dental School's Occlusion and TMJ Dysfunction Service 
(SODAT/FORP-USP).

Patients were mostly females $(n=42,84 \%)$ and ranged in age from 25 to 70 years. Patients, who were suspected to have or were being treated for some type of neoplastic tumors and/or similar conditions were excluded from the study as well as pregnant or possibly pregnant women were excluded from the study to avoid exposure to radiation. A single, previously calibrated and trained examiner performed all clinical and radiographic examinations to ensure reproducible results with higher reliability. The radiographs were numbered by a second person so that there was no identification by the examiner. Radiographic analysis and measurements were performed at 3 consecutive moments with 1-month intervals between them.

All subjects were examined clinically according to Research Diagnostic Criteria for Temporomandibular Disorders - RDC/TMD axis I (13). Clinical assessment involved the measurement of mandibular movements and deviation from the midline using a digital caliper, as well as palpation of masticatory muscles and TMJ to verify the presence of pain and joint sounds. The presence of pain and dysfunction of masticatory muscles was evaluated according to the individual's responses to palpation. Some authors have standardized the areas that should be explored and even the pressure to be applied in order to provide homogeneous criteria diagnoses for clinicians and researchers (13). This is particularly important to confirm the reliability of results obtained in studies involving muscle palpation. The patients indicated the presence or absence of pain on palpation represented by the four-point scoring system according to the RDC: $0=$ no pain or only pressure, $1=$ mild pain, 2 $=$ moderate pain and $3=$ severe pain.

After completion of the RDC/TMD assessment, the visual analogue scale (VAS) was used to evaluate four TMD symptoms pre-selected based on case reports: orofacial pain, headache, tinnitus and dizziness. According to the values of the symptoms as assessed by the VAS score for each symptom it was possible to classify the patients into three groups: Group 1 (severe symptoms, VAS score from 7-10), Group 2 (moderate symptoms, VAS scale from 4-6) and Group 3 (mild symptoms, VAS score from 0-3). The correlation with the measurements performed in the stylohyoid chain was verified among the groups to determine a possible association between the angulation of the styloid process in the anterior and medial directions with the intensity of pain in patients with TMD.

Digital radiographic images of the styloid process were obtained: lateral cephalometric skull radiograph, for analysis of anterior angulation and posteroanterior skull radiograph (reverse Towne's projection) for analysis of medial angulation. All biosecurity criteria were adopted for protection of the operator and patient. The images were digitized and analyzed on the computer screen using Radiocef cephalometric software (Radiomemory, Belo Horizonte, MG, Brazil), which demarcate anatomic points on the digital radiographic image. The software automatically created specific cephalometric analyses and produced linear and angular measurements of the styloid process. Each radiograph was measured and plotted 3 times with 1-month intervals between measurements. The mean values were further analyzed in order to reduce the inter-measurement errors.

For measuring the anterior angulation of the styloid process, the lateral cephalometric skull radiograph was obtained using the technique proposed by Yavuz was used (14), which consisted of mapping the first ear canal and the Frankfurt line. The patient was positioned with the Frankfurt plane parallel to the floor (horizontal) and the median sagittal plane perpendicular to the floor, and was asked to occlude in maximum intercuspation (MI). The cephalometric tracing was performed as follows: a line was drawn from the ear canal to the styloid process apex and a second horizontal line was drawn perpendicular to the Frankfurt line and passing through the lowest point of the external auditory canal, forming an angle (Fig. 1). The three measurements made at 1-month intervals were averaged to a final value of the anterior angulation of the styloid process. The average of each group of patients was correlated statistically with the four TMD symptoms (orofacial pain, headache, tinnitus and dizziness) to observe whether the increase of the angulation was proportional to the increase of the severity of symptoms.

For measuring the medial angulation of the styloid process, the posteroanterior skull radiograph (reverse Towne's projection) was obtained using the technique proposed by Yavuz was used (14). The patient was

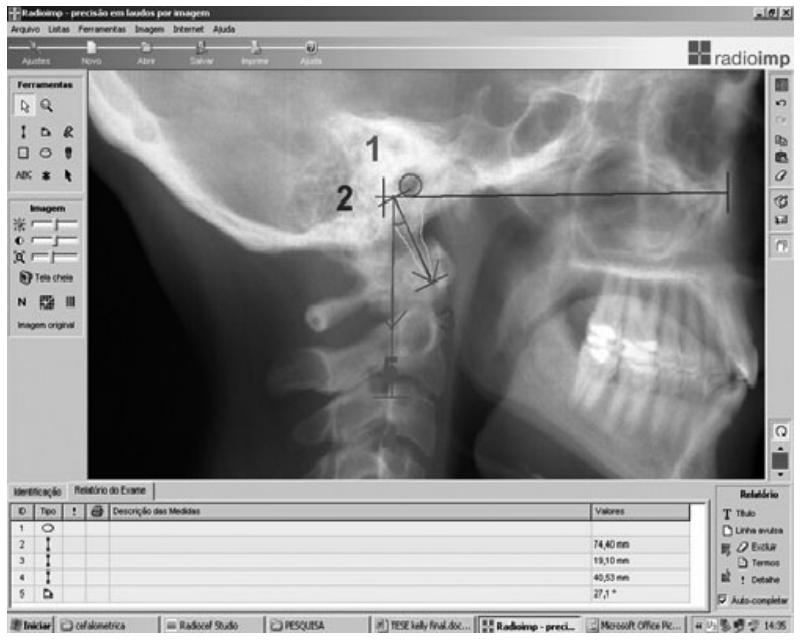

Figure 1. Measurement of the anterior angulation of the styloid process using the lateral cephalometric skull radiograph. 
positioned facing the x-ray equipment with the forehead on a frontonasal support, maintaining the mouth open. First, a horizontal line was drawn passing at base of the skull. A second line was drawn perpendicular to the horizontal line passing through tip of the styloid process, and a third line was drawn along the styloid process from the base of the skull to the apex of the styloid process (Fig. 2). Measurements were made bilaterally. The three measurements of each side made at 1-month intervals were averaged to a final value of the medial angulation of the styloid process at the right side and left side. The average of each group of patients (right side and left side) was correlated statistically with the four TMD symptoms (orofacial pain, headache, tinnitus and dizziness) to determine whether the increase of the angulation was proportional to the increase of the severity of symptoms.

Data obtained with both types of radiographs were subjected to statistical analysis using Biostat Software 4.0. Pearson Correlation test was used for statistical analysis. The significance level was set at 5\%.

\section{Results}

The time of occurrence of symptoms and onset of painful symptoms ranged around 1-20 years, and 16 subjects (32\%) claimed to feel orofacial pain for 10 years or more. Regarding the frequency of pain, 20 subjects (40\%) had orofacial pain all the time and $30(60 \%)$ said that the pain comes and goes. Regarding the current pain, the scores remained between 3-8 in the VAS scale. The interview also revealed that 11 individuals (22\%) already had closed lockjaw, $35(70 \%)$ had the habit of grinding or clenching their teeth while sleeping and 30 (60\%) while awake, 40 $(80 \%)$ reported filling of tiredness on the facial muscles

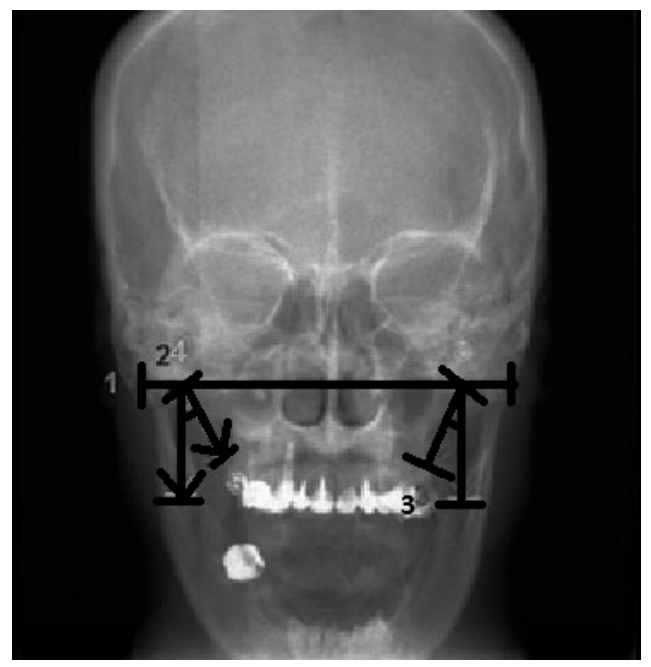

Figure 2. Measurement of the medial angulation of the styloid process using the posteroanterior skull radiograph (reverse Towne's projection). tired upon waking, 9 (18\%) had rheumatoid arthritis or another illness that can affect joints, and 11 subjects (22\%) had suffered a stroke or trauma in the face or jaw.

In the clinical evaluation, regarding the region of pain, 24 (48\%) had pain on the TMJ, 22 (44\%) had pain in the facial muscles and 4 (8\%) in both regions. Ten subjects (20\%) had limited mouth opening $(<40 \mathrm{~mm})$ and the majority had midline shift and deviation on mouth opening. TMJ sounds were checked on palpation and auscultation of the joints with a stethoscope during jaw opening and closing. As a result, 26 individuals (52\%) had some sound on the TMJ during the clinical examination, with the click sound being the mot prevalent followed by a fine and coarse crackle.

Regarding the assessment of symptoms obtained with the VAS scale, orofacial pain was the most common (100\%), followed by headache (92\%), tinnitus (76\%), and dizziness (72\%). Regarding orofacial pain, there were patients without pain (score 0 ) and no patient scored "1 or 2". The group with "mild classification" was comprised of patients whose scores ranged from 3-4, the group with "moderate classification" had scores 5-6 and in the group with "severe classification" the scores ranged were 7-8. One patient scores 9 belonged to the group of patients with "severe classification".

The anterior angulation average of the styloid process was $20.89^{\circ}$. The three measurements performed to were also proven to be highly reproducible due to the high Pearson's correlation coefficient $(r>0.9)$ and $p<0.001$. For the medial angulation of the styloid process, the average was $19.1^{\circ}$ in the right side and $19.04^{\circ}$ in the left side. The three measurements on each side were also correlated by the Pearson's test and had $r>0.9456$ and $p<0.001$ to the right and $r>0.8491$ and $p<0.001$, for the left side indicates a strong correlation between them and low error. A weak correlation ( $r=0.44)$ and a statistically significant difference between the values $(p=0.001)$ were found comparing the average of the 3 measurements taken on the right side and the average of the 3 measurements taken on the left side.

The averages of anterior and medial angulations showed weak correlation with symptoms (Pearson's correlation coefficient), which suggests that the angulation of the styloid process does not influence on the severity of TMD symptoms. The results of the present study was different from those of other studies, which found that the angulation and the length of the styloid process can pressure vessels and nerves, causing pain and worsening of TMD symptoms $(14,15)$.

The average of anterior angulation of the styloid process obtained by measuring the cephalometric radiographs was correlated similarly among the three groups for each symptom. Tukey's test was performed for the data analysis and the result was again $p>0.05$, which means 
that there was no statistically significant difference in the angulation of the groups. However, it can be observed that in the correlation with orofacial pain, the anterior angulation was slightly greater for the group with severe symptoms and it decreased as the intensity of the patients' symptoms diminished. Regarding headache, values and averages showed balance. Regarding the other symptoms, the anterior angulation values tended to be lower in the group with severe symptoms.

Likewise, the medial angulation measurements were correlated among the three groups for each symptom (VALOR DE r) and as a result, there was no statistically significant difference among the groups $(p>0.05)$. There was no increase or decrease in medial angulation with the increase of symptom severity.

\section{Discussion}

The predominance of females $(n=42,84 \%)$ in the study sample is due to the profile of our Occlusion and TMJ Dysfunction Service, which serves more women than men, to the fact that orofacial pain affects women more frequently (16). Thus, it was not possible to establish whether there were gender differences because of the small number of male patients in the sample $(n=8)$. With respect to the accuracy and reproducibility of the measurements, they were performed 3 times to ensure greater reliability and lower errors rate. Pearson's correlation revealed that all measurements were reproducible with a low error rate between measurement intervals. Regarding the radiographic examination, lateral cephalometric radiographs are considered more reliable than panoramic radiographs (17) because they suffer less distortion and produce a more accurate image (18).

In the present study, the anterior angulation of the styloid process ranged from $6.3^{\circ}$ to $39.5^{\circ}$, with average of $20.89^{\circ}$. This value is similar to those reported by Yavutz (14), who found $33.6^{\circ}$ for patients with Eagle syndrome and $21.4^{\circ}$ for control patients. As for the medial angulation, the results were $19.1^{\circ}$ for the right side and $19.04^{\circ}$ for the left side, also similar to the results of Yavutz (14), who found $14^{\circ}$ for the right side and $18.1^{\circ}$ for the left side in the group with Eagle syndrome and $15^{\circ}$ and $16.3^{\circ}$, respectively, in the control group. With these results, this study reveals a reference variation and average anterior and medial angulation found in patients with TMD. Furthermore, the results revealed angular asymmetry of medial styloid processes when evaluated bilaterally $(r=$ 0.4485 and $p=0.0011$ ).

Regarding the incidence of symptoms, $100 \%$ of patients had orofacial pain, 92\% had headache and 76\% and 72\% had some degree of tinnitus and dizziness, respectively. The results of this study replicated what is usually found in the literature and were found (19), who analyzed 4528 patients screened for TMD treatment and observed through a questionnaire, the prevalence of the symptoms most commonly reported. Among the symptoms were found: pain (96.1\% of subjects), headache (79.3\%), and ear discomfort or dysfunction (82.4\%). Studies in the general population revealed the mean prevalence for symptoms of tinnitus in patients with TMD range from $28 \%$ to $76 \%$. While dizziness associated with TMD varies from $5 \%$ to $70 \%$ (20).

In the correlation between symptom severity and morphological alteration of the styloid process, no statistically significance difference was found among length, angle and anterior medial angulation of styloid process in the 3 groups ( $>0.05$ ). However, it was observed that the decrease of the anterior angulation was associated with the increase of the intensity of tinnitus and dizziness in the group with mild TMD symptoms, though without statistical significance. This evidence is justified in the literature by the location of the styloid process because medial to the styloid process, from anterior to posterior, is the internal jugular vein together with the accessory, hypoglossal, vagus and glossopharyngeal nerves. The cranial nerves in combination with carotid arteries that can produce clinical symptoms when stimulated are: $\mathrm{V}$ (trigeminal), VII (facial), IX (glossopharyngeal) and X (vagus). And a posterior deviation of the elongated styloid process can irritate the last four cranial nerves, internal carotid artery and internal jugular vein.

In the medial angulation, no difference was observed in neither statistically or graphically. Thus, this study agrees with the findings of Yavultz (14) who hypothesized that the anterior angulation may have more influence on the intensity of symptoms. There was no statistically significant association between morphological change in length, angulation and anterior medial angulation of the styloid process and TMD symptoms (orofacial pain, headache, tinnitus and dizziness). However, by analyzing the means and standard deviations of measurements in the styloid chain it was observed the trend of larger lengths of the styloid process and smaller anterior angulation in patients with higher pain intensity, especially for tinnitus.

In conclusion, there was no correlation between the intensity of TMD symptoms and the measurements of anterior and medial angulation of the styloid process using either lateral cephalometric or posteroanterior radiographs (reverse Towne's projection). The findings of the present study widen the perspectives for the development of further research on this area that might help enlightening this aspect of TMD.

\section{Resumo}

Este estudo investigou a existência de associação entre a angulação 
do processo estiloide nas direções anterior e medial e a intensidade dos sintomas de disfunção temporomandibular. Cinquenta pacientes (8 homens e 42 mulheres) com idade entre 25 a 70 anos, com sintomas relevantes de DTM foram avaliados. Os exames clínicos foram realizados para determinar a severidade dos sintomas da DTM (dor orofacial, cefaleia, zumbido e tontura) com base nos critérios do RDC / DTM e na escala visual analógica (EVA), e imagens de radiografias digitais do processo estiloide foram obtidas: cefalométrica lateral com incidência reversa (análise de angulação anterior), e póstero-anterior do crânio (projeção reversa de Towne) (análise de angulação medial). A média de angulação anterior do processo estilóide foi $20,89^{\circ}$, enquanto a média da angulação medial foi $19,1^{\circ}$ no lado direito e $19,04^{\circ}$ no lado esquerdo. Não houve diferença estatisticamente significativa entre os grupos de pacientes (sintomas severos, moderados ou leves) em associação com os sintomas de DTM e as angulações anterior ou medial do processo estiloide $(p>0,05)$. Não houve correlação entre a intensidade dos sintomas de DTM e as medidas das angulações anterior e medial do processo estiloide utilizando a radiografia cefalométrica lateral ou a póstero-anterior (projeção reversa de Towne).

\section{Acknowledgements}

The authors are indebted to the financial support granted by CAPES.

\section{References}

1. De Leeuw R. Orofacial pain: guidelines for assessment, diagnosis and management. Quintessence 2008;4:2-5.

2. Atsu SS, Ayhan-Ardic F. Temporomandibular disorders seen in rheumatology practices: a review. Rheumatol Int 2006;26:781-787.

3. Baba K, Tsukiyama Y, Yamazaki M, Clark GT. A review of temporomandibular disorder diagnostic techniques. J Prosthet Dent 2001;86:184-194.

4. Tuz HH, Onder EM, Kisniscin RS. Prevalence of otologic complaints in patients with temporomandibular disorder. Am J Orthod Dentofacial Orthop 2003;123:620-623.

5. Bernhardt 0 , Gesch D, Schwahn C, Bitter K, Mundt T, Mack F, et al.. Signs of temporomandibular disorders in tinnitus patients and in a population-based group of volunteers results of the study of health in Pomerania. J Oral Rehabil 2004;31:311-319.

6. de Souza Carvalho AC, Magro Filho O, Garcia IR Jr, de Holanda ME, de Menezes JM Jr. Intraoral approach for surgical treatment of Eagle syndrome. Br J Oral Maxillofac Surg 2009;47:153-154.

7. Catelani C, Cudia G. Stylalgia or Eagle syndrome: report of a case. Dent
Cadmos 1989:57:70-74.

8. Feldman VB. Eagle's syndrome: a case of symptomatic calcification of the stylohyoid ligaments. J Can Chiropr Assoc 2003;47:21-27.

9. Eagle WW. Symptomatic elongated styloid process: Report of two cases of styloid process-carotid artery syndrome with operation. Arch Otolaryngol 1949;49:490-503.

10. Albuquerque Junior RF, Miller K, Hotta TH, Gonçalves M. Temporomandibular disorder or Eagle's syndrome? A clinical report. J Prosthet Dent 2003;90:317-320.

11. Frommer J. Anatomic variations in the stylohyoid chain and their possible clinical significance. Oral Surg Oral Med Oral Pathol 1974;38:659-667.

12. Strauss $M$, Zohar $Y$, Laurian $N$. Elongated styloid process syndrome: intraoral versus extraoral approach for styloid surgery. Laryngoscope 1985;95:976-979.

13. Dworkin SF, Leresche L. Research diagnostic criteria for temporomandibular disorders: review, criteria, examinations and specifications, critique. J Craniomandib Disord 1992;6:301-55.

14. Yavuz H, Caylakli F, Yildirim T, Ozluoglu LN. Angulation of the styloid process in Eagle's syndrome. Eur Arch Otorhinolaryngol 2008;265:1393-1396.

15. Ilguy D, Guler N, Bayirli G. Incidence of the type and calcification patterns in patients with elongated styloid process. J Int Med Res 2005;33:96-102.

16. Laster WS, Ludlow JB, Baley $\amalg$, Hershey HG. Accuracy of measurements of mandibular anatomy and prediction of asymmetry in panoramic radiographic images. Dentomaxillofac Radiol 2005;34:343-349.

17. Ongkozowito EM, Dieleman MMJ, Kuijpers-Jagtman AM, Mulder PGH, Van Deck JW. Linear mandibular measurements: comparison between orthopantomograms and lateral cephalograms. Cleft Palate Craniofac J 2009; 46:147-153.

18. Cooper BC, Kleinberg I. Examination of a large patient population for the presence of symptoms and signs of temporomandibular disorders. Cranio 2007;25:114-126.

19. Camparis CM, Formigoni G, Teixeira MJ, De Siqueira JT. Clinical evaluation of tinnitus in patients with sleep bruxism: prevalence and characteristics. J Oral Rehabil 2005;32:808-814.

20. Urban VM, Neppelenbroek $K H$, Pavan $S$, Alenar Júnior FGP, Jorge JH, Almilhatti HJ. Association between otalgia, tinnitus, dizziness and hypoacusia, with temporomandibular disorders. RG0 2009;57:107-115.

Received October 5, 2012 Accepted December 8, 2012 